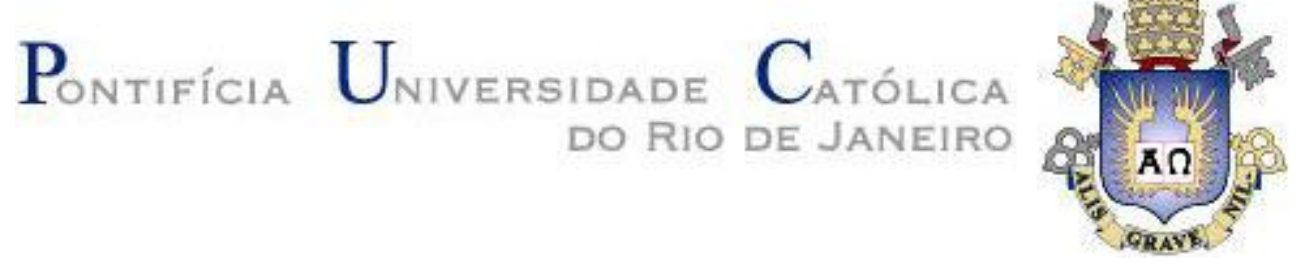

Catarine de Jesus Barros Sobral

\title{
O TDAH em Adultos
}

\author{
Monografia apresentada ao \\ Programa de Pós-Graduação em \\ Psicologia da PUC-Rio como requisito \\ parcial para obtenção do título de \\ Especialista em Avaliação \\ Neuropsicológica.
}

Orientadora: Helenice Charchat Fichman

Rio de janeiro

Setembro de 2018 


\section{AGRADECIMENTOS}

Gostaria de agradecer especialmente aos meus pais por sua dedicação e amor, a minha tia Marília (in memória) por sua dedicação e amor fraternal incomparável e ao meu filho Bernardo por proporcionar uma visão totalmente extraordinária do mundo materno.

Gostaria de especial agradecimento a Professora Helenice Charchat pela oportunidade de fazer parte deste projeto tão especial e por toda aquisição de conhecimentos. A Andreza Moraes por sua atenção e dedicação na nossa busca de conhecimentos. 


\section{RESUMO}

O TDAH em adultos é um transtorno deveras estudado mas ao mesmo tempo muito difícil de ser diagnosticado apenas na fase adulta. Antigamente acreditava-se que este transtorno não era passível em adultos e que apenas poderia ser diagnosticado a partir dos 12 anos. Atualmente sabe-se que desde a inclusão em contexto escolar o TDAH é visto como um transtorno as crianças no processo de aprendizagem. Estudou-se os sintomas e estruturas neuropsicológicas que caracterizam o TDAH em adultos, além de traçar um perfil neuropsicológico e salientar métodos e terapêuticas utilizadas atualmente para o tratamento em adultos com diagnostico de TDAH.

Palvras-chaves: TDAH em adultos, Funções executivas e o TDAH, TDAH.

\section{Abstract}

ADHD in adults is a disorder that has been a long time studied, but are very difficult to diagnose in adulthood because they're more able to children. It was formerly believed that this disorder wasn't amenable to adults and could only be diagnosed from age 12 onwards. Currently knowns since inclusion in the school context ADHD is seen as a children's disorder in the learning process. We studied the neuropsychological symptoms and structures that characterize ADHD in adults, as well as to draw a neuropsychological profile and highlight methods and therapeutics currently used for treatment in adults with ADHD diagnosis.

Keywords: ADHD in adults, Executive functions and ADHD, ADHD. 


\section{SUMÁRIO}

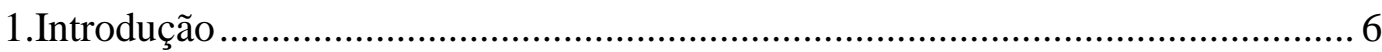

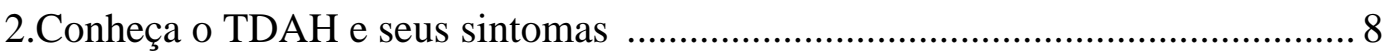

3.A natureza e Funções Cognitivas encontradas no TDAH ............................... 12

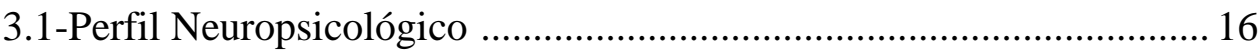

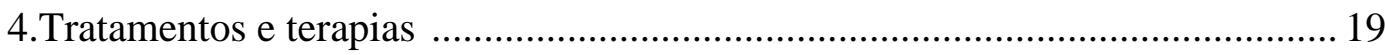

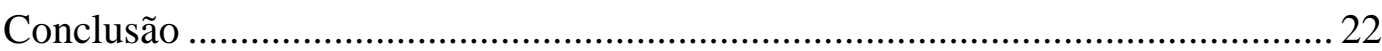

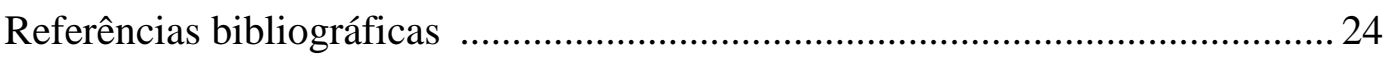




\section{INTRODUÇÃO}

Desorganização, procrastinação, comportamento impulsivo, desatenção e/ou indecisão são comportamentos que nos deparamos em quase todos os momentos de nossas vidas cotidianas. No entanto, quando esse "estilo de vida moderna" promove um grau de desconforto excessivo, trazendo prejuízos muitas vezes marcantes poder-se-à estar perante o transtorno do Deficit de Atenção e hiperatividade (TDAH).

Quando se estuda sobre TDAH, concomitantemente, fala-se na dificuldade de atenção concentrada, isto é, crianças geralmente diagnosticadas como hiperativas perdem mais facilmente o foco e com isso poderá afetar a aprendizagem. Estudá-lo em sua forma adulta do transtorno é um processo maturativo unitário, uma vez apenas 2,5\% a 8\% da população geral adulta é diagnosticada (Saboya E, et al, 2009). Não obstante, é comum histórias de adultos com pouca organização, impulsivos, ansiosos e com pouca tolerância a frustração, ou até mesmo aqueles que estão sempre em busca de novos estímulos ou iniciam vários projetos e os abandonam por falta de motivação.

Para alguns autores, bem como Mattos (2006), o TDAH caracteriza-se por três sintomas básicos: desatenção, impulsividade e hiperatividade física e mental. Segundo o DSM-5 (2014), poderá predominar um ou mais dos três sintomas supracitados. Acomete-se em ambos gêneros, independente do grau de escolaridade, cultural ou nível socioeconômico. Todavia, poderá resultar em prejuízos na qualidade de vida da pessoa acometida.

Atualmente é classificada no DSM-5 como um transtorno do neurodesenvolvimento com padrão persistente de desatenção e/ou hiperatividade-impulsividade que interfere no funcionamento ou desenvolvimento da pessoa (Maria Ines Nascimento et al., 2014). Com as alterações ocorridas no DSM-5 percebeu-se uma consonância com o avanço dos estudos da Neuropsicologia, mais especificamente, pelas articulações do cérebro, cognição e comportamento, isto é, o funcionamento mental típico, atípico e as sua relações entre mente e cérebro (Oliveira R. , 2006). 
Inicialmente procurar-se-á apresentar os constructos, definições e sintomatologia apresentadas no transtorno em adultos, em seguida os sintomas e sua morfologia tendo em atenção as funções que são afetadas, em seguida, possivelmente, o perfil neuropsicológico apresentado em adultos com TDAH e finalmente os tratamentos e terapias. Provavelmente, os tratamentos apresentados não serão, por si só exaustivos a literatura encontrada, todavia, ir-se-á proporcionar apenas algumas estruturas de tratamentos que são mais pertinentes na atualidade. 


\section{CONHEÇA O TDAH E SEUS SINTOMAS}

Atualmente existem muitos estudos acerca do TDAH tanto em crianças quanto em adultos, em especial depois do seu reconhecimento no início do século passado, no qual foi introduzido no DSM-II nas desordens comportamentais da infância e adolescência como Transtorno de Reação Hipercinética, mas apenas no DSM-IV$\mathrm{R}^{\mathrm{TM}}$, que acrescentou a tríade sintomatológica: desatenção, hiperatividade e impulsividade, passando assim, para Distúrbio do Déficit de Atenção/Hiperatividade (Paulo Mattos et al, 2006). Dados epidemiológicos apontam sua prevalência ao redor do mundo de 4 a $10 \%$ entre crianças e 1 a $6 \%$ em adultos (Biederman e Faraone, 2005 apud (Marcelo Schimitz, Guilherme Polanczyk e Luiz Augusto Paim Rohde, 2007). Alguns estudos apontam que apenas um terço das crianças com diagnóstico oferece remissão dos sintomas na idade adulta, ao passo que ao longo do desenvolvimento poderá apresentar quadros subsindrômicos ou com prejuízo significativo (Daniel Fuentes, 2014).

Sendo assim, o TDAH é deveras estudado, contudo existem controvérsias em relação aos resultados sobre a estimativa de persistência, muito provavelmente, pelas diferenças metodológicas empregadas nos estudos, como idade, números de sintomas, formas de relatos e etc. Alguns estudos alteram algumas escalas de autorelato com estruturação muito ampla e outros já com estruturas mais abrangentes. Outros estudos estudam a sintomatologia com base na história do desenvolvimento (anamnese) mas esses relatos são pouco confiáveis. Em um estudo longitudinal, Barkley (2011) assinala uma escala de 39 sintomas em adultos que poderão colaborar no diagnóstico, demonstrando a abrangência excessiva que poderá alcançar.

Realizou-se uma compilação de alguns sintomas apresentados na literatura abrangente o qual é apresentado na tabela a seguir, listando alguns comportamentos típicos que poderão ser associados ao TDAH no adulto: 


\section{Impulsividade:}

$\checkmark$ Geralmente reage ao mundo externo com atos impulsivos pois funciona como receptor de alta sensibilidade que reage automaticamente sem avaliar as características do objeto gerador, por exemplo, age e depois pensa;

$\checkmark$ Para alguns pode parecer: "Você pega o bonde parado, fica nele até certo ponto e depois cai. O bonde continua e você fica para trás" O relato de um paciente poderá ser caracterizado por lapso de dispersão;

$\checkmark$ Os lapsos de dispersão poderão gerar dificuldade de organização temporal, relacionamento interpessoal, levando a pessoa a gerar um esforço demasiado para a realização de tarefas cotidianas e resultando em menor durabilidade e desempenho;

$\checkmark$ Problemas de autoestima, minimização de situações de risco, como olhar antes de atravessar a rua;

$\checkmark$ Dificuldade de praticar esportes;

$\checkmark$ Esquecimentos excessivos de atividades corriqueiras como desligar o gás, entre outros;

$\checkmark$ Dificuldade de manter-se num emprego, grupo social ou relacionamento por longo período de tempo;

$\checkmark$ Impulsividade verbal e/ou comportamentos de tentativa de defesa de qualquer ação;

$\checkmark$ Poderá apresentar comportamentos agressivos, descontrole alimentar, uso de drogas, gastos demasiados, compulsões variadas como para jogos, tagarelice incontrolável, entre outros;

$\checkmark$ Poderão entrar em vários projetos ao mesmo tempo, afirmando a necessidade de viver intensamente;

\section{Hiperatividade física e mental:}

$\checkmark$ Em adultos tem tendência a se manifestar menos assintomática, podendo ou não apresentar hiperatividade física, provavelmente apresentando-se como adequação formal, no entanto, observa-se uma necessidade de 
movimentação excessiva de partes do corpo, como balançar das pernas, rabiscar papel, roer unha, entre outros;

$\checkmark$ Por procurar manter a atenção por maior tempo e demandar de esforço para controlar os impulsos, apresentam maior cansaço mental;

$\checkmark$ Tendência a interromper conversas, fala de forma exacerbada e constante, muda de assunto e comete erros de fala, leitura ou escrita, dificuldade de dormir por excesso de pensamento podem ser consideradas características da hiperatividade mental e/ou desatenção;

$\checkmark$ Tem sempre a sensação de que não consegue realizar atividades de forma eficiente, muitas vezes poderá apresentar um julgamento equivocado;

$\checkmark$ Está sempre pensando em algo e tem muita dificuldade de parar de pensar

\section{Instabilidade da atenção:}

$\checkmark$ Esse sintoma sempre aparecerá no TDAH adulto;

$\checkmark$ Por apresentar uma tempestade incessante de pensamentos, tem dificuldade de canalizar seus esforços na realização de trabalhos com metas e prazos pré-estabelecidos;

$\checkmark$ Desvia facilmente a atenção, mesmo por pequenos estímulos;

$\checkmark$ Provavelmente devido ao déficit atencional tem dificuldade de monitoramento temporal, muitas vezes perde-se em atividades que gosta ou tem dificuldade de finalizar outras. É muito comum ouvir relatos de parentes informando que fica horas no banheiro se arrumando para sair para o trabalho, ou que demora para conseguir sair de casa para algum evento. Desorganização cotidiana, tendendo a perder objetos, atrasar-se ou faltar compromissos ou pagamentos. Essa dificuldade vê-se, também, na dificuldade de focar numa conversa, tendendo a captar apenas "pedaços" da conversa, ou em leituras de um texto ou até mesmo como ouvinte em uma palestra;

$\checkmark$ Presença de hiperfoco em assuntos de maior interesse, mas também apresenta dificuldade de permanecer em atividades obrigatórias em especial que precisa se manter parado ouvindo o outro; 
Conforme supracitado, o tripé 'Desatenção, impulsividade, hiperatividade' está presente nos adultos com TDAH, embora se apresente de maneira diferente que nas crianças. Segundo Barkley (2011) adultos apresentam maior predominância a desatenção do que a hiperatividade, além disso, tendem a desenvolver estratégias compensatórias para lidar com seus déficits. Não obstante, a desatenção, tanto no adulto quanto na criança, é um sintoma e não a sua causa. Segundo o DSM-5 (Maria Ines Nascimento et al., 2014) a desatenção e desorganização preconizam na dificuldade da pessoa em permanecer em uma ou mais tarefas durante um determinado período de tempo, já a hiperatividade e/ou impulsividade implicam no "excesso de atividade, inquietação, incapacidade de permanecer sentado, intromissão em atividades de outros e incapacidade de aguardar". Portanto, o TDAH é caracterizado por um padrão persistente de desatenção, hiperatividade e impulsividade, são de origem neurobiológica, e decorrentes da dificuldade de controle inibitório e reações impulsivas, que muito provavelmente persistirão na idade adulta, resultando em prejuízos no funcionamento social, acadêmico e profissional (American Psychiatric Association [APA], 2013 apud DSM-5 2014).

Segundo Barkley (2011) o TDAH é mais como uma dimensão que está dividida entre sintomas e prejuízos: um é a maneira como um transtorno se expressa em pensamentos e ações e o outro são consequências adversas que resultam na demonstração dos sintomas. 


\section{A natureza e as Funções Cognitivas encontradas no TDAH}

Segundo Barkley (1997 apud Paulo Mattos et al, 2006) o TDAH é a expressão de um déficit central de inibição da atenção e impulsividade, afetando consequentemente a memória. A desatenção deriva de uma disfunção executiva, maioritariamente caracterizada pela dificuldade de controle inibitório. As consequências desse processo inibitório deficitário seriam responsáveis pelas sintomatologias de baixa tolerância, alta necessidade de recompensa imediata, falta de um comportamento governado por regras, falha na previsão das consequências e emissão de respostas rápidas, porém imprecisas. Para Paulo Mattos (2006), o TDAH é uma disfunção em área do córtex cerebral ocasionando dificuldades relacionadas à concentração, memória, hiperatividade e impulsividade.

Mas afinal, o que são funções executivas? As funções executivas são um conjunto de processos metacognitivos que juntos permitem que o indivíduo se envolva em comportamentos complexos e direcionados a metas (Gonçalves, 2014). Ou seja, correspondem a um conjunto de habilidades integradas que permitem direcionar comportamentos a objetivos, avaliar e planejar de forma eficaz a adequação desses comportamentos, abandonar estratégias ineficazes em prol de outras e, consequentemente, resolver problemas de forma imediata, médio e/ou longo prazo

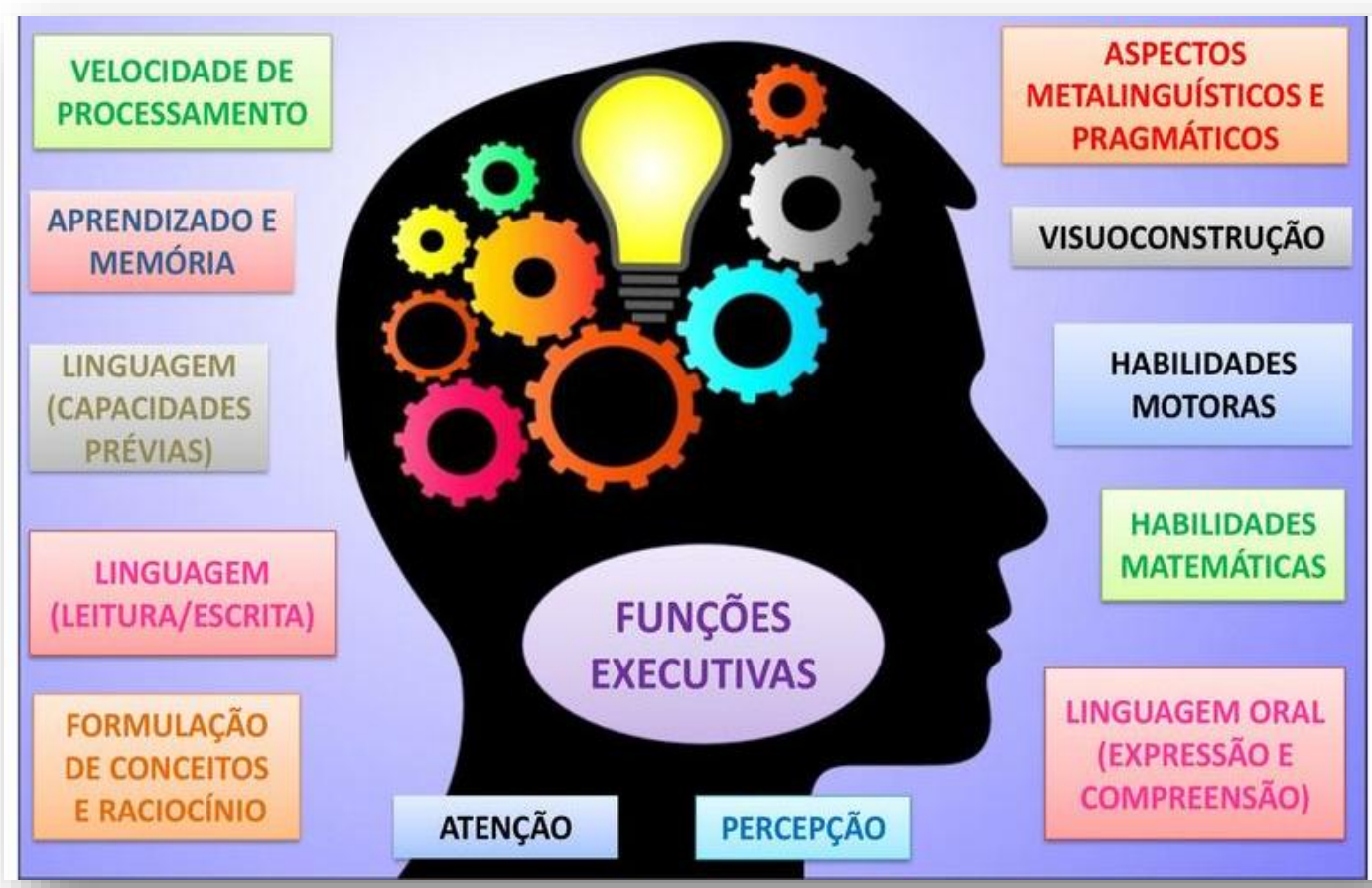


(Lezak, Howieson, \& Loring, 2004 apud Gonçalves, 2014). Diversos estudos têmse mostrado que geralmente a disfunção executiva ocorre por um comprometimento no córtex pré-frontal e/ou nos circuitos relacionados e que diversos transtornos neurológicos e psiquiátricos poderão estar vinculados a uma disfunção executiva, bem como depressão ou esquizofrenia. Podem ser divididas em três grandes categorias de competências:

1. Autocontrole: Caracterizado pela capacidade de resistir "à uma tentação" para poder fazer aquilo que é certo. Essa capacidade ajuda a prestar atenção, agir menos impulsivamente e a manter a concentração numa tarefa, isto é, o autocontrole é uma ferramenta muito importante para realização de tarefas que precisam de inibir distratores, os quais podem ser internos (pensamentos intrusivos) como externos. Esta habilidade ajuda em tarefas em ambientes ruidosos ou até mesmo prestar atenção em uma conversa interessante numa festa, por exemplo.

2. Memória de trabalho: Capacidade de manter informações na mente, onde elas podem ser manipuladas. Essa habilidade é necessária para realizar tarefas cognitivas, tais como estabelecer uma relação entre dois assuntos, fazer cálculos apenas com a mente e estabelecer uma ordem de prioridade entre várias tarefas. Também chamada de memória operacional pois é muito importante na estruturação de realização de tarefas da vida cotidiana. É responsável por reter as informações-chave necessárias para a solução de um problema, reter fonemas e palavras até que eles possam ser recuperados na ordem correta ou ser integrados em ideias significativas. A Memoria operacional, também é responsável por conseguir integrar informações novas a um conhecimento anterior. Ela é necessária tanto para nossa compreensão de problemas e criação de resoluções como para a compreensão e produção da linguagem. $\mathrm{Na}$ infância, principalmente, diversos estudos têm correlacionado a capacidade de memória operacional com desempenho acadêmico.

3. Flexibilidade cognitiva: A capacidade de usar o pensamento criativo e ajustes flexíveis para se adaptar às mudanças. Essa habilidade auxilia as crianças a utilizar sua imaginação e criatividade para resolver 
problemas. Ou seja, é a habilidade de mudar o foco atencional, as prioridades ou as regras para adaptar-se às demandas do contexto. Por exemplo, se adaptar bem à mudanças de rotina ou de planos; inventar ou aceitar bem formas alternativas de resolver um problema; não ter dificuldade em substituir uma informação ultrapassada por uma atual, etc.

Portanto, as funções executivas são habilidades que cada indivíduo vai construindo e inter-relacionando-as entre si. Suas disfunções não apenas são sinais de transtorno, podem, apenas apresentar-se em diferentes "graus": mais leves ou mais graves. Contudo, as disfunções são muito comuns no TDAH, para Barkley é uma condição sine qua non, essencialmente no controle inibitório. Sendo este visto como um déficit no gerenciamento atencional. Não obstante a modulação da atenção, não é uma condição especifica no diagnostico, como será estudado com maior afinco mais adiante, mas muitas vezes é de extrema intensidade.

Conforme assinalado, algumas tarefas, em especial que surtem maior interesse, faz com que o indivíduo possa apresentar hiperfoco. Entretanto, enfrentam problemas com controle voluntário e auto-direcionado do foco. Por outro lado, a hiperatividade representa um déficit em inibição motora, assim como a impulsividade está relacionada a uma inibição pobre dos impulsos.

Portanto, pode-se afirmar que o TDAH é uma condição neurobiológica caracterizada por um déficit no gerenciamento atencional e algumas vezes por diversas alterações no processamento executivo, podendo ou não estar acompanhado de impulsividade e hiperatividade afetando crianças, adolescentes e adultos (Lopes, Nascimento \& Bandeira, 2005; Wahlstedt, 2009 apud Gonçalves, 2014). No DSM-IV ${ }^{\mathrm{TR}}$ assinala-se o surgimento dos sintomas por volta dos 7 anos (APA, 2013 apud Oliveira e Dias, 2018), mas, tem-se reparado que tal quesito vem se intensificando até mesmo na primeira infância, em especial com a entrada no núcleo escolar.

Não obstante, sua permanecia tende a ser ao longo do ciclo vital em aproximadamente 70\% dos casos (Lara et al., 2009 apud Oliveira e Dias, 2018). No que se refere a sintomatologia, vem ao logo do desenvolvimento da criança se 
modificando, e com isso surgem os comportamentos compensatórios. Estes muitas vezes como forma de tentativas para diminuir os sintomas mais incomodativos. $\mathrm{Na}$ fase adulta, observa-se mais a desatenção pela evitação do que a hiperatividade, na forma de inquietação interna ou desconforto e a impulsividade pode aparecer em tomadas de decisões impulsivas, ou seja, sem pensar nas suas consequências (Conners, 2009 apud Oliveira e Dias, 2018). Alguns autores acreditam que a mente de um TDAH funciona como um receptor de alta sensibilidade que reage automaticamente, sem avaliar as características do objeto gerador de estímulo. Mas percebe-se que o comprometimento das funções executivas é o centro do problema, afetando a atenção, mas não só. Afeta, também, a capacidade de planejamento, execução de tarefas, organização, manejo do tempo, memória de trabalho, regulação emocional, iniciação e persistência de tarefas. Nos adultos este comprometimento frequentemente aparece como dificuldade em terminar tarefas no prazo determinado, atrasos frequentes, esquecimento de tarefas planejadas, entre outros.

A nível morfológico, indivíduos com TDAH geralmente apresentam afecção nas áreas do Sistema Atencional Anterior e Posterior. O primeiro composto pelas áreas da região frontal incluindo o Córtex Pré-Frontal, Córtex Cingulado Anterior e Estruturas de Base, como Gânglios de Base e Corpo Estriado. O segundo composto pelo Tálamo e Lobo Parietal. A nível neuroquímico os neurotransmissores mais importante nas sinapses é a dopamina e a noradrenalina. Os quais muitas vezes apresentam em maior quantidade nos TDAH. Portanto, as funções executivas tornam-se hiperativadas uma vez que a região pré-frontal é responsável pela elaboração do raciocínio abstrato, alternância de tarefas, planejamento, organização de atividades, que por sua vez dependem da fluência verbal e da memória operacional para poder monitorar e inibir comportamentos indesejados. Sem o amadurecimento preciso dessa região provavelmente terá dificuldade em tarefas que exigem controle inibitório, flexibilidade mental e principalmente controle da atenção (Daniel Fuentes, 2014).

Sendo assim, adultos com pouco amadurecimento das regiões corticais supracitadas poderão ter dificuldade no gerenciamento atencional, processamento da informação, flexibilidade cognitiva, controle inibitório, ou seja, nas funções 
executivas quentes e frias. A distinção entre o componente "frio" das funções executivas, são as funções que envolvem habilidades cognitivas, como, a capacidade de fazer cálculos mentais, já a componente "quente", reflete a capacidade de regular as emoções, como por exemplo, a capacidade de controlar a raiva.

\section{III.a Perfil Neuropsicológico}

Ter o diagnóstico de TDAH em um adulto é deveras difícil, pois seus sintomas têm sua expressão no âmbito das atividades próprias da sua faixa etária. Assim, a hiperatividade observada em crianças pode corresponder a um excesso de atividades em adultos e a impulsividade pode se expressar em términos prematuros de relacionamentos, problemas de humor, abuso de substâncias ou direção impulsiva de veículos. A desatenção em adultos pode ser evidenciada em tarefas que exigem organização e sustentação da atenção ao longo do tempo e nas dificuldades com a memória (Mattos et al., 2006). Além dos sintomas virem mascarados, o TDAH pode estar acompanhado de comorbidades que dificultam o diagnóstico preciso, principalmente em mulheres (Lopes et al., 2005 apud (Gonçalves, 2014)). Em um estudo de prevalência brasileiro demonstrou que quase $70 \%$ dos diagnósticos foram realizados em mulheres adultas o que se diferencia do que os critérios atuais sugerem de que a prevalência deve ser maior no gênero masculino (American Psychiatry Association, 2014 apud Gonçalves, 2014).

A avaliação neuropsicológica demonstra ser uma ferramenta deveras fundamental no diagnostico desse transtorno, uma vez que a apresentação clínica do TDAH é heterogênea, seus sintomas e perfil cognitivo variam entre indivíduos com esse transtorno, podendo contribuir para examinar as potencialidades e dificuldades de cada individuo de forma unitária, favorecendo a elaboração de estratégias eficazes na estimulação cognitiva. Além disso, os dados neuropsicológicos poderiam auxiliar o clínico em casos onde o diagnóstico se mostra mais obscuro. Na medida em que os critérios diagnósticos para o TDAH enfatizam sobremaneira à desatenção e hiperatividade/impulsividade, deve-se ter em atenção que nos adultos existem diversas controvérsias inirentes à própria descrição dos sintomas. 
Segundo Barkley (1997 apud Paulo Mattos et al, 2006) o TDAH é a expressão de um déficit central de inibição da atenção e impulsividade, afetando consequentemente a memória. A desatenção deriva de uma disfunção executiva, maioritariamente caracterizada pela dificuldade de controle inibitório. As consequências desse processo inibitório deficitário seriam responsáveis pelas sintomatologias de baixa tolerância à espera, alta necessidade de recompensa imediata, falta de um comportamento governado por regras, falha na previsão das consequências e emissão de respostas rápidas, porém imprecisas. Já para Paulo Mattos (2006), o TDAH é uma disfunção em área do córtex cerebral ocasionando dificuldades relacionadas à concentração, memória, hiperatividade e impulsividade.

Sendo assim, muito provavelmente um adulto com TDAH poderá apresentar os dificuldade de concentração em tarefas com esforço cognitivo (percebe-se uma dificuldade controle inibitório, muito provalvemente pelo déficit no gerenciamento atencional. Isto é, adultos com TDAH apresentam maior dificuldade em tarefas com atenção dividida do que concentrada e seletiva, não obstante, apresenta índices médio a médio inferiores nestas duas ultimas. Ou seja, tem maior dificuldade de realizar duas tarefas ao mesmo tempo. Visualizou-se, também, confusão/desorientação e perda do curso do pensamento com muita facilidade. Dificuldade de se manter no mesmo emprego ou relacionamento durante um longo período de tempo. Baixa intolerância à frustração, déficits de memória e problemas de localização espacial, principalmente quando está dirigindo, sendo que todos esses sintomas parecem se relacionar com déficits de atenção concentrada, dividida e seletiva.

No que se refere à impulsividade/hiperatividade, respostas precipitadas antes das perguntas serem completadas, dificuldade em aguardar sua vez, intromissão na conversa dos outros, problemas diários, provavelmente, são derivados pelos baixos índices de organização e planejamento. Há dificuldades em priorizar as tarefas e suas decisões na maioria das vezes são tomadas de forma impulsiva, o que invariavelmente, acaba por trazer algum tipo de prejuízo.

Em síntese, Geralmente são adultos com índice de coeficiente de inteligência global médio a médio superior, pois apresenta um bom rendimento verbal, mas a nível de memória operacional, organização perceptual e velocidade de processamento 
apresentam-se médio a médio inferior. Nos Subtestes Dígitos e Sequência de Números e Letras apresenta maior dificuldade e em muitos indivíduos foi possível observar algumas características peculiares de pacientes com TDAH, como agitação psicomotora e sonolência em tarefas que exigem esforço mental.

Nos testes de Atenção Concentrada geralmente apresentam mais omissões do que erros. A nível da precisão geralmente apresentam resultados medianos. Tem grande dificuldade de iniciarem tarefas demostrando hesitação e em alguns casos fuga, mas quando estimulados externamente, inibe esse movimento e chega a realizar a tarefa. Alguns estudos de casos (Gonçalves, 2014, Barkley, 2011) demonstram memória semântica de longo prazo e Memória Visual de Curto Prazo com índices medianos a médio inferiores e muitas vezes optam por deixar de lado.

Sendo assim, pode-se afirmar que indivíduos adultos com perfil de TDAH apresentam disfunções executivas quente e frias. Entre os componentes executivos sobressai o déficit de controle inibitório, memória operacional, planejamento e organização, priorização de tarefas, tomada de decisão, gerenciamento atencional, irritabilidade, motivação e modulação do afeto. Contudo, apresentam maior construção em fluência verbal, processamento de inferências, velocidade de processamento e resolução de problemas simples. 


\section{TRATAMENTO E TERAPIAS}

Embora os sintomas de hiperatividade e impulsividade possam diminuir ao final da adolescência, na idade adulta os sintomas de desatenção, inquietude e impulsividade se mantem em graus diferenciados. Os sintomas têm uma expressão no âmbito das atividades, como por exemplo, a hiperatividade em adultos poderá ser vista como um workaholics. A impulsividade pela dificuldade em manter-se em empregos ou relacionamento afetivos. E a desatenção poderá ser evidenciada em diálogos, eventos sociais ou em tarefas que requerem organização, sustentação da mesma por um longo período e até esmo na dificuldade de memorização de tarefas cotidianas, como por exemplo, esquecer eventos importantes, reuniões, consultas medicas, compromissos em geral. Mas segundo o CID-10 para o diagnostico do TDAH em adultos precisa-se ter em atenção a necessidade de apresentar sintomas de desatenção, hiperatividade e impulsividade. Excluindo o diagnostico na presença de comorbidade com ansiedade e depressão.

Não obstante, alguns tratamentos e terapêuticas tem sido implementados, bem como, o uso de medicação como Metilfenidato, mais precisamente a Ritalina ${ }^{\circledR}$, no brasil, mais conhecimento comercialmente como Concerta ${ }^{\circledR}$. Tanto na literatura abrangente quanto nas redes sociais sobre o assunto comum encontrarmos depoimentos de adultos diagnosticados destacando após a comprovação do transtorno e a tomada medicamentosa houve uma mudança radical em suas vidas de forma positiva. Mas por outro lado, existe um outro grupo que assinala que o diagnóstico produz o sentimento de "ser um TDAH" e procuram combater os processos de medicalização, expõe o desconforto individual e social relatado pelos seus usuários, em especial se a tomada desta medicação é realizada a longo prazo. Existem alguns pacientes, que em contexto analítico, informam que tomar Ritalina ${ }^{\circledR}$ sente-se "acorrentando dentro do próprio corpo", outros sentem a falta em especial em contexto escolar, pois indicam que ela ajuda a prestar a atenção. a longo prazo ela apresenta alguns efeitos colaterais que muitas vezes têm de ser tratados em psicoterapia. 
A nível de estimulação cognitiva, o modelo de auto-regulação de Barkley tem sido um dos mais importantes. A inibição comportamental é o primeiro componente do modelo e a base para os outros. Ela permite internalizar e modelar as quatro funções executivas, que para ele são fundamentais no déficit executivo apresentado pelos pacientes com TDAH: memória de trabalho não verbal, memória de trabalho verbal, regulação do afeto e reconstituição (planejamento e organicidade). Com o desenvolvimento das $\mathrm{FE}$, o inidividuo poderá ter controle dos comportamentos indesejados e com isso inibi-los para que possa não sobrecarregar a memória de trabalho. A inibição dos comportamentos indedejados é um dos primeiros pontos a serem trabalhados nas terapias segundo esse modelo. Com ela, o terapeuta é um auto-regulador externo inicialmente, para que no futuro o indivíduo consiga potencial para se autorregular e gerenciar o seu processo atencional. Um segundo passo é a auto-regulação: resposta do indivíduo que muda o seu próprio comportamento, de maneira a alterar a probabilidade de uma consequência posterior. É uma ação que implica uma preferência por gratificações retardadas maiores do que por gratificações imediatas menores. Para que tal possa ocorrer precisa-se passar por um momento de auto-aprendizagem e inibição dos pensamentos indesejados para que haja autocontrole e consequentemente não sobrecarregar a memória de trabalho. Sendo assim, neste momento, uni as respostas comportamentais e suas consequências mesmo com grandes intervalos de tempo entre elas. Esse trabalho também ajuda na construção da organicidade temporal e na capacidade de criar estratégias para o seu cotidiano, a partir de experiências passadas e de utilizar esses elementos para organizar e executar comportamentos.

Para Barkley a memória de trabalho não verbal, sobrecarregada priva as atividades sensório-motoras; já a verbal priva da fala e alça fonológica. A regulação emocional priva o comportamento emocional e de seus aspectos motivacionais.

É provável que a inibição comportamental auxilie este processo de supressão das ações autodirigidas observáveis que vão dar origem às funções executivas (internalização do comportamento). A inibição comportamental e as quatro funções executivas que ela sustenta influenciam o sistema motor, contrapondo-se ao seu controle total pelo ambiente imediato ao possibilitar que o comportamento seja regulado a partir de informações internas, da noção de mudança temporal. Desta 
forma, a funções executivas tornam-se possíveis e respostas motoras novas, complexas são estruturadas, de modo direcionado para alcançar objetivos mais eficazes.

Para esse modelo a atenção sustentada é um grande aliado pois possibilita o controle do comportamento por meio de informações representadas internamente. O controle de interferências irá atuar para que não apresente respostas para distrações internas ou externas. Segundo Barkley (2011) existem dois tipos de atenção sustentada, uma primeira aquela que é mantida pelo reforço imediato e é orientada por fatores externos, por exemplo os jogos de videogames, e a persistência voltada para objetivos, que é orientada internamente. A Persistente é a mais prejudicada no TDAH, por isso que existe uma forte intolerância a frustração e consequentemente desistência, resistência ou até mesmo fuga das atividades. No caso para se trabalhar a atenção sustentada, o indivíduo deve ter em mente o objetivo da tarefa e seu plano para alcançá-lo, isto é organicidade mental, a fim de que sirva como modelo para construir as estruturas comportamentais necessárias para essa finalidade. Deve, também, incitar, manter e renovar as fontes internas de motivação que sustentam o comportamento rumo ao objetivo, na ausência de fontes externas de reforço ou motivação. 


\section{CONCLUSÃO}

O diagnóstico de TDAH apenas na idade adulta é deveras conturbado, uma vez que a descrição dos sintomas não são muito adequados para adultos. Mattos et al (2006) e Barkley (2011) procuraram realizar uma listagem de sintomas que fossem de encontro com pesquisas longitudinais e o DSM, não obstante, essas listas tornamse muitas vezes longa e ambivalentes. Não obstante, estudos longitudinais demonstram a incidência e permanência dos sintomas ao longo da vida dos indivíduos, mesmo dissociando do pensamento passado de que o TDAH dissipavase com a entrada na fase adulta.

O diagnóstico de TDAH no adulto permanece sendo clinico, obtido através de uma avaliação cuidadosa com emprego de critérios clínicos definidos tanto pelo DSMV quanto Wender-Utah, além do emprego de escalas como a ASRS de Mattos (2006), avaliações neuropsicológicas, exames neuroimagens, entrevistas semiestruturadas, coletas de dados com outras fontes de informações como pais, tios, avós, irmãos, entre outros e identificação do comprometimento.

Perante essas estratégias é importante assinalar que o perfil neuropsicológico é deveras importante para o auxílio no diagnóstico, uma vez que o TDAH apresenta um perfil maioritamente de disfunção executiva, quentes e frias. Ao longo desse estudo, pode-se perceber que o déficit de gerenciamento atencional, controle inibitório, organicidade e planejamentos percorrem todo o desenvolvimento do TDAH, mesmo este criando mecanismos de compensação.

Sendo assim, estratégias terapêuticas como tomada medicamentosa de Metilfenidato®, mais conhecido como Ritalina ${ }^{\circledR}$ e psicoterapia centrada no modelo de auto-regulação de Barkley poderão ser ferramentas fundamentais para o desenvolvimento de mecanismos para uma qualidade de vida desses indivíduos.

Não obstante, mesmo com o avanço e a qualidade dos estudos longitudinais em adultos com TDAH, deve-se ter em conta que ainda são muito deficitários, apresentando uma carência no campo de estudos que possam contribuir de forma eficaz para a metodologia e estrutura de como esse transtorno afeta o cotidiano dos adultos acometidos. Tanto porque até mesmo a sua heterogeneidade ainda não está totalmente verificada, as influencias que os efeitos colaterais e o uso prolongado 
dessa medicação nos seus consumidores e será que apenas a auto-regulação é um método funcional para o sucesso.

"Do jeito que a vida está

Eu não quero crescer

Tanta volta que a vida dá

Eu não quero crescer

Eu não quero estudar

Eu não quero me formar

Eu não quero trabalhar

Eu não quero ter que pagar

Eu não quero me decepcionar

Eu não quero entristecer

Eu não quero crescer"

(Música “Eu não quero crescer”, de Pitty)

O trecho desta música remete a uma realidade que faz parte da formação humana: ao longo do desenvolvimento e busca pela independência, maior se torna o desafio e as múltiplas demandas de habilidades e competências que precisam ser estruturadas para que possam garantir um dia-a-dia eficaz. Ao longo de um simples dia o indivíduo precisa tomar decisões que muitas vezes são difíceis, saber controlar as emoções e impulsos, ter disciplina, flexibilidade, planejamento, ser criativo, administrar a rotina, dentre milhares de outras coisas. Mas será que já se pensou em quais são as funções necessárias para que se possa dar conta de todas essas necessidades? Será que é possível ter uma boa estruturação sináptica para que se consiga atender a esses tipos de demandas? 


\section{REFERENCIA BIBLIOGRAFICA}

Barkley, R. A. (2011). Vencendo o TDAH: Adulto. Porto Alegre: Artmed.

Daniel Fuentes, L. M.-D. (2014). Neuropsicologia: Teoria e prática. Porto Alegre: Artmed.

Dias, C. O. (2018). Psicoeducação do Transtorno do Déficit de Atenção/Hiperatividade: O que, como e para quem? Temas em Psicologia, 243-261. doi:10.9788/TP2018.1-10Pt

Gonçalves, M. d. (2014). Funções executivas em um caso de TDAH adulto: a avaliação neuropsicológica auxiliando o diagnóstico e o tratamento. Revista Neuropsicologia Latinoamerican, 35-41. doi:DOI: 10.5579/rnl.2013.0214

Marcelo Schimitz, Guilherme Polanczyk e Luiz Augusto Paim Rohde. (2007). TDAH: remissão na adolescencia e preditores de persistencia em adultos. Jornal Brasileiro de Psiquiatria, 25-29.

Maria Aparecida da Silva et al. (2014). Health-related quality of life in adults with attention-deficit and hyperactivity disorder. Medical Express, 1, 43-46. doi:http://dx.doi.org/10.5935/MedicalExpress.2014.01.10

Maria Ines Nascimento et al. (2014). Manual diagnóstico e estatístico de transtorno DSM-5. Porto Alegre: Artmed.

Oliveira, R. (2006). Introdução à neuropsicologia e organização funcional do cerebro. Formação Humana em Geriatria e Gerontologia: uma perspectiva interdisciplinar, p. 344.

Paulo Mattos et al. (2006). Painel brasileiro de especialistas sobre diagnóstico do transtorno de déficit de atenção/hiperatividade (TDAH) em adultos. Revista de Psiquiatria do Rio Grande do Sul, 28(N.1), 50-60. doi:http://dx.doi.org/10.1590/S0101-81082006000100007

Paulo Mattos et al. (2011). Validade de constructo e confiabilidade da versão em língua portuguesa do Questionário de Qualidade de Vida em Adultos que apresentam TDAH. (3, Ed.) Psiquiatria Clinica, 38, 91-96. doi:http://dx.doi.org/10.1590/S0101-60832011000300002

Saboya E, et al. (2009). Executive functions in adult ADHD. Dement Neuropsychological, 3, 34-37.

Silva, A. B. (2014). Mentes Inquietas: TDAH: Desatenção, Hiperatividade e Impulsividade. São Paulo: Editora Globo. 